\title{
Factors Affecting Brand Switching Behavior in Telecommunication Industry of Pakistan: A Qualitative Investigation
}

\author{
Muhammad Abdul Rauf Shah"1, Mudassir Husnain' ${ }^{2}$, Amir Zubairshah ${ }^{1}$ \\ ${ }^{1}$ Lahore Business School, University of Lahore, Sargodha Campus, Sargodha, Pakistan \\ ${ }^{2}$ Faculty of Management Sciences, International Islamic University, Islamabad, Pakistan \\ Email: Mudassir.phdmkt14@iiu.edu.pk, mabdulraufshah@gmail.com
}

How to cite this paper: Shah, M.A.R., Husnain, M. and Zubairshah, A. (2018) Factors Affecting Brand Switching Behavior in Telecommunication Industry of Pakistan: A Qualitative Investigation. American Journal of Industrial and Business Management, 8, 359-372.

https://doi.org/10.4236/ajibm.2018.82022

Received: November 5, 2017

Accepted: February 23, 2018

Published: February 26, 2018

Copyright $\odot 2018$ by authors and Scientific Research Publishing Inc. This work is licensed under the Creative Commons Attribution International License (CC BY 4.0). http://creativecommons.org/licenses/by/4.0/

\section{Open Access}

\begin{abstract}
The purpose of the study is to investigate the factors effecting brand switching behavior of customers in telecommunication industry of Pakistan. A qualitative approach has been employed to measure the relationships between the variables of the study. Primary data was collected through the use of in-depth interview technique; open-ended questionnaire is used while transcripts were analyzed drawing from sample of education department. NVivo 11 version has been used to determine the relationship and to validate the study. This paper explores findings from a qualitative data through face-to-face interview about tendency of customers brand switching behavior towards telecommunication industry. The in-depth interviews revealed that quality of service, influence of family, friends \& relatives and price structure were among the determining factors that influence customers' satisfaction towards brand switching behavior. This research is limited only to mobile service providers in northern regions of Pakistan. Similar research could be employed in other regions of country and may be extrapolated to other verticals of telecom industry. This study assessed the influence of four variables whereas switching behavior may also be influenced by some other variables that have not been captured. Hopefully, this study will give great understating to telecom industry managers to formulate their strategies specifically suited to esteemed customer and leads towards customer retention. This study provides some valuable recommendations to practitioners to develop policies to ensure that there is enhanced quality of service, affordable and attractive packages for family members. Family and friends should be given more importance to suit different people and offer continuous sale-promotions to its customers.
\end{abstract}

\section{Keywords}

Telecomm Service, Customer Satisfaction, Switching Behavior, Mobile Users 


\section{Introduction}

Telecommunication industry has become extraordinary part of today's dynamic and modern world. As the market becomes more mature, mobile communication services become more homogeneous and the competition for acquiring new customers and retaining the existing customers becomes more intense, and as a consequence customer satisfaction is a critical factor for mobile service providers to maintain and to improve their market share and profitability [1]. In competitive environment, organizations must consider other factors to maintain their customers to get distinctive competitive edge. Therefore, to remain competitive in the market, mobile operators have to identify the factors related to consumer satisfaction and loyalty [2]. Efficient retention management encountered these factors accounted for customer dissonance and intrigue customer to switch from one service to other. After the introduction of mobile number portability, the mobile user's switching turnover is more [3]. Mobile number portability is the process by which one user can move to another operator of one's choice, but keep the existing number.

On the same lines, it has equally been observed that cellular network users subscribe for specific network connections and switch to others when they find that their current services do not fulfill their specific communication needs and other networks are providing better services. Brand switching regarding cellular companies are becoming very important because it has both aspects that one company is losing their customers while other company is getting customer at same time. The globalization of competition, saturation of markets, and development of information technology have enhanced customer awareness and created a situation where long-term success is no longer achieved through optimized product price and qualities. In telecommunication industry, switching behavior is increasing dramatically due to factors like price, trust, customer satisfaction, customer services, inconvenience, perceived expectations, perceived quality, service quality, brand image and price perception. In today's challenging economy and competitive business world, retaining your customer base is critical to your success; if you don't give your customers some good reasons to stay, your competitors will give them a reason to leave.

The customer behavior study is basically the psychology of customers, like when, how, why and people buy and use the products for satisfying their needs. Every customer bears their own choice, behavior, attitude and perception for different categories of brands. Most of the time customers switch from one brand to another brand considering different factors. When customer is dissatisfied from one brand, then they replace it by another one which provides them maximum services. In competitive environment, organizations must consider other factors to maintain their customers to get distinctive competitive edge. For the purpose of achieving the maintained competitive edge, the telecommunication industries are compelled to carve innovation and to execute the best thing for the satisfaction of their customer's. 
Generally, companies in the telecommunication industry work closely with their customers to determine competitive pricing indicators, quality of service indicators along with other anticipatory factors that help determine future need and services. One of the drivers of customer retention is customer satisfaction which is achieved by ensuring that the customer gets need satisfying products and services. It is, therefore, important to understand the needs of the customer and provide solutions in the form of products and services that actually meet those needs. Researchers elaborated in their studies that how factors influence the customer satisfaction and switching behavior in cellular services of Pakistan. The important research gap in this study is how telecommunication firms meet customers' expectations towards a particular service provider. Previous studies used the method of quantitative research but this study is based on qualitative research.

In this study, an attempt is made to examine factors that may influence brand switching behavior of telecom users. The specific objectives are to understand the relationship between brand switching behavior and the different factors of the telecommunication operators and to determine the possible reasons to switch users from one telecommunication operator to another.

\section{Literature Review}

Determinants of brand switching in mobile service providers in Southern Punjab are important factors that influence switching behaviors and preferences of customers in telecom industry regarding mobile service providers. So, it sounds as a major problem for the telecommunication service providers, especially for the mobile telecommunication service providers to deliver quality service consistently as changes in market compositions and competing characteristics have been surfacing incessantly. Brand switching behaviors of customers are increasing dramatically day by day due to service failure, customer satisfaction, price, inconvenience and customer services and companies are facing many issues in results like customer churn, lose of market share, low profitability etc.

\subsection{Price}

There are three components to the concept of price: objective price, perceived non-monetary price, and sacrifice [4]. The objective monetary price (simply put, the amount of money paid for product) is not equivalent to the perceived price (that is, the price as understood and recorded in the mind of customer) since customers do not always know or remember the actual price paid for a product. Price plays a vital role in telecommunication market, especially for the mobile telecommunication service providers. The correlation between price and customer loyalty which explains that satisfaction of customers in telecom market depends on factors like attractive call rate, internet browsing fees, price schedule variation and so on. The perception of price fairness plays an important role in any exchange transaction. The feeling of fairness depends on the gain-loss ratio 
felt by both partners in the exchange. From the customer's perspective, the gain is the product to be received, whereas the loss is the money to be paid. Price is a vital impact on switching behavior of customer to switch from one service provider to another. As in telecommunication industry, the brand switching cost is relatively low, so customers easily switch to another network, which offers competitive prices and quality. In this regard, operators should be more careful in determining and maintaining price structure of call and variety of services offered to customers, otherwise switching tendency of customers across operators will be increased and resulting lessening the loyalty of customers.

\subsection{Brand Image}

Brand concept has been frequently discussed in marketing literatures. Brand building is not only an important driving force for marketing physical products, it is also a vital issue for service firms [2]. It is thought as the perception or mental picture of a brand formed and held in customers' mind, through customers' response, whether rational or emotional [5]. It is revealed through literature that positive brand image results in greater brand equity and customer preference towards a brand due to its market position and due to the higher demand of the brand among their social circle. Brand image also help companies to attract other network users and prevent customer switching behavior for their current customers. According to [6] increase in brand image or identity will also increase customer loyalty to the brand simultaneously. It is therefore concluded that a positive brand image is supposed to meet customer's expectation and offer more benefits to customer, which may lead to customer satisfaction and trust.

\subsection{Quality of Service}

In the telecommunication industry the quality of services is identified through innovation, communication and value added services. Quality of service is not only an important factor of customer satisfaction in manufacturing industries but also in service firms. It also shows indirect relation as mediating with customer relation and quality of services linked with brand loyalty in prospects of telecom industry regarding cellular services. When the customers will not get the quality of service which they were expecting before the purchase their trust will shake which in turn makes the customer dissatisfied and this ends up in customer switch to other service provider. So it can be concluded that if customer finds the best quality of service conveniently, they would be less price sensitive and be loyal.

\subsection{Family, Friends and Relatives}

Social factors are societal norms, values and sagas are also affecting the buying behavior of customers like reference groups, family members and role \& status of each member in society. It may be noted that family, friends and relatives have positive impact on customer satisfaction thus increasing customer reten- 
tion. According to [4] customer always keep in mind their family or friends are using which network in choosing a network. The reasons for switching network from one to another as any of the family members have that network connection. Researcher also suggests that cellular provider should invest on network coverage, better FNF offers (Family and friends packages) and finally get feedback from customer to improve their services continuously to avoid the behavior of switching.

\subsection{Customer Satisfaction as Mediator}

Customer satisfaction can be defined as the evaluations made by customers based on all the purchase experiences, disregarding any specific purchase experience. Accordingly, in the present study we will conceptualize customer satisfaction as the overall consumption perception of customers when using mobile communication services. Service switching intention is conceptualized a customers' desire to replace the current service provider with another competitor; and consequently we define the switching intention as a negative consequence of a service company, referring to the likelihood of a customer switching the current mobile service provider to another one. Organizations' success is totally dependent on the customer satisfaction. Improvements regarding betterment of price, quality services and good brand image would certainly lead to greater customer satisfaction. Customer satisfaction is one of the key factors in modern marketing and customer behavior analysis. Customer satisfaction has positive effects on the customer retention so Mobile operators should shift focus on building corporate image and analyze more carefully the reason for customers to switch brands in this industry in order to increase loyalty among these customers. Therefore any bad service will most probably be experienced by a customer, which results in customer's dissatisfaction and leading towards brand switching.

\subsection{Customer Switching Behavior}

Brand switching occurs when a customer switches their allegiance from one brand of a certain type of product to another brand. Brand switching behavior has long been of interest to marketing researchers at modeling brand switching behavior and providing a useful representation of the influence past purchase on current purchase [7]. Customer behavior is the psychological processes that customers carry out in recognizing needs, identifies the means to resolve these needs and making purchase decisions. Evidence shows that price, inconvenience, and quality of service are important factors that affect the customers brand switching behavior. Companies can maintain long-term relationship with customers and prevent their behavior towards switching their brand. Brand switching regarding cellular companies are becoming very important because it has both aspects that one company is losing their customers while other company is getting customer at same time. But in prospects of customer arbitrary behavior are becoming alarming for companies to sustain their customers and to reduce 
customer turn rate as long term customer relationship means long term profitability. It may be concluded that, when any company loses a customer they are not only losing future earnings but incurring the cost of finding new customers as well.

\subsection{Hypotheses}

Based on the afore-mentioned theoretical relationships among study variables, this research proposed the following four hypotheses:

Hypothesis 1. Multiple components of customer switching intention uncovered in the first phase of this study are significantly associated with customer satisfaction.

Hypothesis 2. Customer satisfaction is significantly associated with customer switching behavior.

Hypothesis 3. Customer satisfaction has a significant mediating role in the relationship between each predictor factor and customer switching behavior.

\section{Conceptual framework}

Based on concept, theory and thinking result, conceptual framework used in this study is a development from the previous study on the analysis between variable of price, brand image, quality of service, family, friends \& relatives factor toward the customer satisfaction to customer switching behavior towards telecommunication industry of Pakistan. We can gain a quick overview of the overall customers witching behavior with the help of the following Figure 1.

These five measures were considered for the purpose of this study in order to understand the parameters of customer switching behavior. The three theoretical methods that define customer loyalty as perceived in this research are viewed from the intangible perspectives. Customer switching behavior is therefore viewed by the researchers to utilize the following three approaches; "Attitudinal Approach" by [8], "Behavioral Approach", and "Composite Approach" by [9] [10].

\section{Methodology}

\subsection{Approach}

Current study follows the qualitative research method to measure the relationships between the variables that affect customer switching behavior identified in

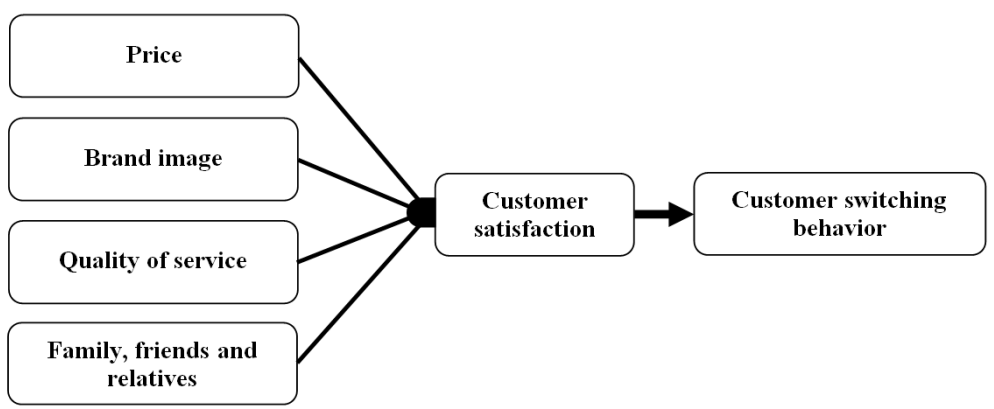

Figure 1. Factors that affect customer switching behavior. 
the literature review in telecommunication industry in Pakistan. Qualitative research was first used by anthropologists and sociologists as a method of inquiry in the early decades of 20th century, although it existed in a non-structured form much earlier. Qualitative research provides an opportunity to explore how things happen in every action, and thus the research results that will be obtained in accordance with the reality that happened. Qualitative research is used to uncover trends in thought and opinions, and dive deeper into the problem [11].

\subsection{Sample}

The study is limited to cellular network providers in northern areas of Punjab province. A convenience sample of respondents was selected. A total of 20 cellular network users from education department were sampled and 16 interviews were completed. Six participants who completed interviews were excluded because their comments were highly inconsistent. Each interview lasted for about 45 minutes to 60 minutes. During the interview, the researcher listened carefully and allowed the interviewee plenty of time to answer the questions. While transcripts were prepared by researchers for the interviews to remove inconsistencies if found later at analysis stage. Follow up questions were asked in order to seek and encourage elaboration in order to avoid making any assumptions as to the meanings of the words or phrases used by the interviewee. Further, measures were also undertaken to ensure respondents were qualified to participate in the study. The sampling did not have the objective of being representative of any particular industry. Although, the sampling was planned to be representative with respect to geographic region, due to this, we acknowledge the limitations of the study.

\subsection{Data Collection}

The technique used was the in-depth, personal interview and a semi-structured interview guide was designed according to insights gained from the literature on dissatisfaction and switching behavior. Participants were asked about the brand, price structure, quality of service, influence of family, friends \& relatives and their satisfaction factors and the reasons behind their decisions. Questions on cellular networks availability in their areas, behavior of franchise representatives, helpline representatives and their query solving time and response were also asked. The exploratory and qualitative nature of the study allowed interviewers to probe participant responses to better learn about their behaviors. The study has based on both primary and secondary sources of data. Secondary research was conducted first. The secondary data was collected from different international and local publications; include internet articles, publications of similar studies.

\subsection{Data Analysis Technique}

All the ten interviews were reviewed several times before being transcribed. The 
most commonly used technique is Thematic Analysis. This technique examines and search for patterns or themes within the data. In present study, data collected from interviews was analyzed within NVivo11 using word cloud method for a variety of themes using a coding scheme and for consistencies and inconsistencies within the overall narrative of each interview.

\section{Analysis}

The transcripts were read through several times and simultaneously notes were made of what was being said and meant by the interviewee in each sentence. Interviews were coded initially using descriptive and NVivo codes within and across interviews [12]. The transcripts were imported into NVivo 11, a computer assisted data analysis package, which facilitated reading and re-reading to identify themes to enable data management and facilitate the analysis.

\section{Price}

Respondents commented that they tended to search for information about alternatives price structure. Five respondents gathered factual information about prices of other service providers. Three of these reduced their purchasing from their existing service provider due to increase in prices; one respondent mentioned that there was no alternative provider as the supplier is the only major player in that region. Another stated that he will take no time to switch on availability of alternative. A respondent mentioned that because they were operating in the not for profit sector, they had to put up with their existing service provider as they offered a lower price than competitors. For example, one respondent commented:

"I remain trying to get new one with cheaper prices, and look and see if there are some real alternatives with fair price structures."

\section{Quality of service}

Respondents commented that they remain to search a telecommunication service provider with good quality of service. Three respondents commented that without good quality of service in cellular network the purpose of using is in-vane. One respondent commented that if there is not good quality of service than it better to convey message by myself instead of making a call. For example, one respondent commented:

"The existing service provider's quality of service is good, and that was one of the reasons why they stayed with that provider."

\section{Family, friends and relatives}

Respondents commented that they prefer a cellular network provider that gives more cheaper packages for family members, friends and relatives. Four respondents commented that if a network cannot facilitate family members and friends then it is very difficult to remain with that network. A respondent mentioned that one of the reasons that they would still continue to purchase from the existing service provider is because they would like to support their family, friends and relatives with cheaper price structure. For example, one respondent 
commented:

We are dissatisfied with existing service provider but only reason to remain with that is they offer family and friend packages.

\section{Brand image}

Respondents commented that brand image has greater impact in other industries but in telecommunication industry only brand image cannot fulfill the customer satisfaction. Five respondents commented that when there will be no quality of service, high prices, poor network what will we do with brand image. Two respondents commented that a network who has brand image he has all qualities then he maintains brand image in the market. For example, one respondent commented:

"We are only satisfied with good quality, strengthen network, easy availability, cheaper prices, we don't know what is brand image. We will give the brand image to that network that fulfills our requirements."

\section{Customer satisfaction}

Respondents commented that customer satisfaction has greater impact on their switching behavior. Five respondents commented that if they will be satisfied with existing one then they will not switch to other cellular network. Two respondents commented that if a network will keep our care why we will switch to other one. For example, one respondent commented:

"If a cellular network fulfills our requirement then we will be fully satisfied and will never think about switching to other one."

\section{Results and Discussion}

Results from the interviews reveal that the respondent's dissatisfaction reasons given includes failure of service, unfair price increases, inadequate customer service, failure to deliver promises, service provider's inability to help customers overcome problems in the industry, poor responsiveness, lack of consistency in the quality of core service, not facilitating family members, friends and relatives, not understanding customer expectations, and not being accountable for perceived problems caused by the service provider. In all but one instance, respondents mentioned that this dissatisfaction occurred with the main or sole service provider, and that their dissatisfaction occurred on continuous basis or in waves over the past six months instead of a one-off problem. Further, respondents mentioned that they perceived the series of problems to be major. Exogenous variables which are price, quality of service, brand image and family, friends \& relatives directly or indirectly influence endogen variable that is customer switching behavior. The influence of variable price, quality of service and family, friends \& relatives to displacement customers through customer satisfaction is getting smaller, and therefore the satisfaction of an intervening variable that can minimize customer switching.

The interviews provide evidence that all the interviewees were aware about customer satisfaction and the customer switching behavior on the basis of price 
structure, quality of service and factor of family, friends and relatives. Findings of this study are consistent with the arguments of most past studies that relates to tendency of customer toward the brand switching behavior in telecommunication industry [13]. In this paper using word count method, word clouds were drawn to examine the customer switching behavior. A primary word cloud was drawn on the basis of primary data gathered through in-depth interviews and secondary data word cloud was drawn on the basis of previous similar studies conducted. Word clouds are attached as Appendix. Both word clouds were analyzed to view the frequency of words that have appeared in NVivo word cloud themes. In primary data word cloud price, quality of service, influence of family, friends \& relatives and customer satisfaction were appeared as most prominent. In secondary data word cloud price, quality of service, brand image and customer satisfaction were appeared most prominent. Comparison of both word clouds reveals that price and quality of service are common whereas brand image has not got attention in primary data word cloud and family, friends and relatives has not been appeared in secondary data word cloud. Therefore, it is revealed that price structure, quality of service and influence of family, friends and relatives have positive effect on customer satisfaction towards customer switching intention. The same results were also found to be true across individuals, cultural context and product categories [3] [5] except the influence of family, friends and relatives that was not highlighted in previous similar studies conducted. It was also observed that brand image was found positive affecting on customer satisfaction in previous similar studies conducted [2] whereas in present study brand image is negative correlating customer satisfaction towards customer switching behavior as influence of culture may be a plausible explanation for the emergence of dimensions that differ from those in the original model.

The current research proposed and tested a theoretical framework for understanding the relationships among price, quality of service, brand image and influence of family, friends \& relatives and customer satisfaction towards brand switching behavior. The result explores that price structure, quality of service and influence of family, friends \& relatives have significant affect on customer satisfaction thus confirming $\mathrm{H} 1$ except brand image that has been verified as negative correlating towards customer satisfaction. It was further verified that customer satisfaction is significantly associated with customer switching behavior thus confirming $\mathrm{H} 2$. The proposed mediating impact of customer satisfaction was verified by examining the indirect effect of predictor variables on customer switching behavior thus validating $\mathrm{H} 3$. Overall, all objectives were successfully achieved through these procedures. The findings of this research study are confirming the impact of price structure, quality of service, influence of family, friends and relatives and other factors, which have the significant effect towards stimulating and de-motivating the behavior of telecom users regarding keeping loyal with existing brand or switch towards another brand. 


\section{Recommendations}

\subsection{Limitations and Scope for Future Research}

The present research is limited in its scope wherein it explores the customer switching behavior factors on cellular mobile services. As this research was limited only to mobile service providers in northern region of Punjab province due to convenience the same research can be conducted in other regions of $\mathrm{Pa}$ kistan and same research may be extrapolated to other verticals of telecom industry such as equipment vendors, broadband providers, personal computer industry, mobile industry and other industries as customer switching behavior is an important factor for creating a differential advantage for all service industries. This study assessed the influence of four variables on consumer intention to switch to new service providers in the mobile telecommunication industry in developing country context. The present study is limited in terms of the predictive power of the research model validated. Despite the model's small predictive power, it offers an initial insight into the possible determinants of a relatively new concept in the switching behavior literature in the telecommunication service industry.

The implication is that switching back behavior may be influenced by some other variables that have not been captured. Thus, the small predictive power of the model provides avenues for research to examine other critical factors that can affect consumers' switching behavior such as internet facility, relationship marketing, social influence, peer influence, persuasive advertising, apology as well as the moderating role of demographic and religious factors. Future research should extend the research model to incorporate these other variables that can help explain better the concept of consumer switching behavior in the marketing and consumer behavior research.

\subsection{Managerial Implications of the Research}

The research findings can be used by cellular service providers while formulating their customer relationship management strategy, while formulating their marketing strategy as well as their customer switching behavior strategy. The findings of this research convey a strong message to cellular service providers that since service delivery or service performance is the major factor affecting customer satisfaction for cellular mobile services, hence it is very important that cellular service providers should stress on perfect service quality. They must ensure that service delivery is consistent as far as quality of voice service, network coverage, data connectivity and speed are concerned. Customers need to feel that they are getting excellent service at appropriate charges; that is, they are getting value for money.

A manager must understand that a culture needs to be built in the organization wherein employees are trained to care for the customers, handle their complaints with patience, be responsive while delivering service and make the customer feel valued. As the employees interact with the customer on an ongoing 
basis they can communicate the customer requirements to the service provider which in turn will help them in formulating their marketing strategy.

A well formulated marketing strategy suited to satisfy the customer will lead to customer retention [14]. A manager must understand that the word cloud analysis has indicated price factor, quality of service factor and family, friends \&relatives' factor also have an impact on customer satisfaction for cellular services. Hence a manager should ensure that it is communicated to the customer that the service offering has been designed keeping in mind his requirements. They also need to ensure that new services and new technologies are introduced at a faster pace. The brand image or reputation of a service provider will also make the customer feel proud to own services so marketing communications play an important role in creating customer satisfaction [15]. Managers must ensure that there is enhanced quality of service, affordable and attractive packages for family members, friends and relatives should be given more importance to suit different people, offer continuous sale-promotion to its customers, enact strategies to ensure that there is sale-promotion of telecommunication operators and appreciated by its customers.

\section{Conclusion}

This study assessed the influence of four variables, namely price, quality, image and influence family on satisfaction and switching behavior of customers in telecommunication industry of Pakistan. A qualitative approach has been employed to measure the relationships between the variables of the study. Primary data was collected through the use of in-depth interview technique; open-ended questionnaire is used while transcripts were analyzed drawing from sample of education department. The in-depth interviews revealed that quality of service, influence of family, friends \& relatives and price structure were among the determining factors that influence customers' satisfaction towards brand switching behavior. This study provides some valuable recommendations to practitioners to develop policies to ensure that there is enhanced quality of service, affordable and attractive packages for family and friends. They should be given more importance to suit different people and offer continuous sale-promotions to its customers.

\section{References}

[1] Zhang, S., Zhao, L., Lu, Y. and Yang, J. (2016) Do You Get Tired of Socializing? An Empirical Explanation of Discontinuous Usage Behaviour in Social Network Services. Information \& Management, 53, 904-914. https://doi.org/10.1016/j.im.2016.03.006

[2] Donald, R.O. (2015). Exploring the Relationship between Relationship Marketing, Relationship Quality and Customer Loyalty in Nigerian Telecommunication Industry. Global Journal of Emerging Trends in e-Business, Marketing and Consumer Psychology, 1, 269-281.

[3] Venkatachalam, V. and Harikaran, S. (2015) Consumer Behaviour towards MNP 
Service with Special Reference to Coimbatore City. International Journal of Research in Humanities, Arts and Literature, 3, 25-30.

[4] Zeithaml, V.A. (1988) Customer Perceptions of Price, Quality, and Value: A Means-End Model and Synthesis of Evidence. Journal of Marketing, 52, 2-22. https://doi.org/10.2307/1251446

[5] Dobni, D. and Zinkhan, G.M. (1990) In Search of Brand Image: A Foundation Analysis. Advances in Customer Research, 17, 110-119.

[6] Ibok, N. and Etuk, G.S. (2015) Brand Identity and Customer Loyalty: Evidence from the Nigeria Telecommunication Industry. International Journal of Managerial Studies and Research, 3, 1-8.

[7] Bass, F.M. (1974) The Theory of Stochastic Preference and Brand Switching. Journal of Marketing Research, 11, 1-20. https://doi.org/10.2307/3150989

[8] Bennett, R. and Rundle-Thiele, S. (2002) A Comparison of Attitudinal Loyalty Measurement Approaches. Journal of Brand Management, 9, 193-209. https://doi.org/10.1057/palgrave.bm.2540069

[9] Dick, A.S. and Basu, K. (1994) Customer Loyalty: Toward an Integrated Conceptual Framework. Journal of the Academy of Marketing Science, 22, 99-113. https://doi.org/10.1177/0092070394222001

[10] Oliver, R.L. (1999) Whence Customer Loyalty? Journal of Marketing, 63, 33-44. https://doi.org/10.2307/1252099

[11] Banzuela, M.A.S., Lopez, V.A.C., Natividad, H.R. and Jonas, V.R. (2015) Level of Satisfaction of MangInasal Customers in STO. Tomas Batngas. Laguna Business and Accountancy Journal, 1, 104-117.

[12] Saldaña, J. (2015) The Coding Manual for Qualitative Researchers. Sage, London.

[13] Haryanto, J.O., Moutinho, L. and Coelho, A. (2016) Is Brand Loyalty Really Present in the Children's Market? A Comparative Study from Indonesia, Portugal, and Brazil. Journal of Business Research, 69, 4020-4032.

[14] Kotler, P. (2015) Framework for Marketing Management. Pearson Education, India.

[15] Bravo, R., Buil, I., de Chernatony, L. and Martínez, E. (2017) Managing Brand Identity: Effects on the Employees. International Journal of Bank Marketing, 35, 2-23. 


\section{Appendix}

Primary data word cloud (Based on-depth interviews)

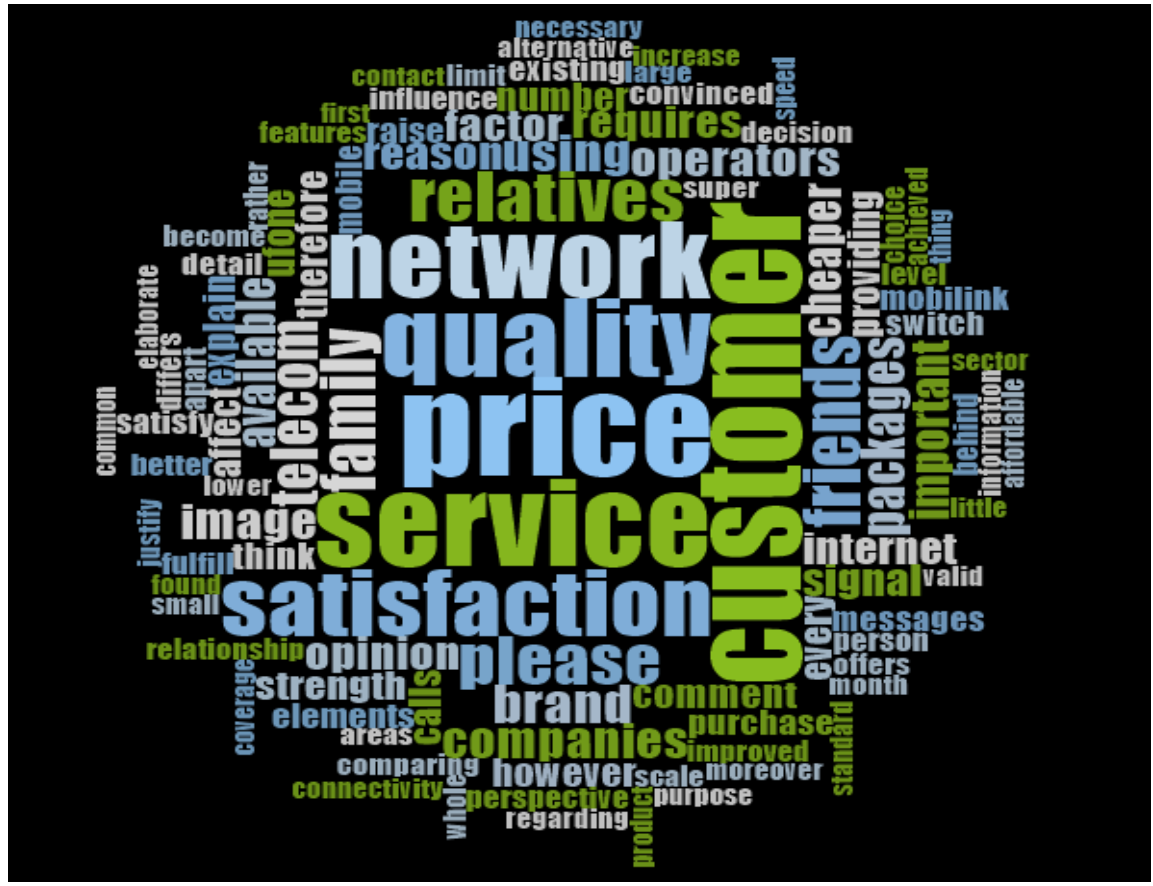

Secondary data word cloud (Based on past similar studies)

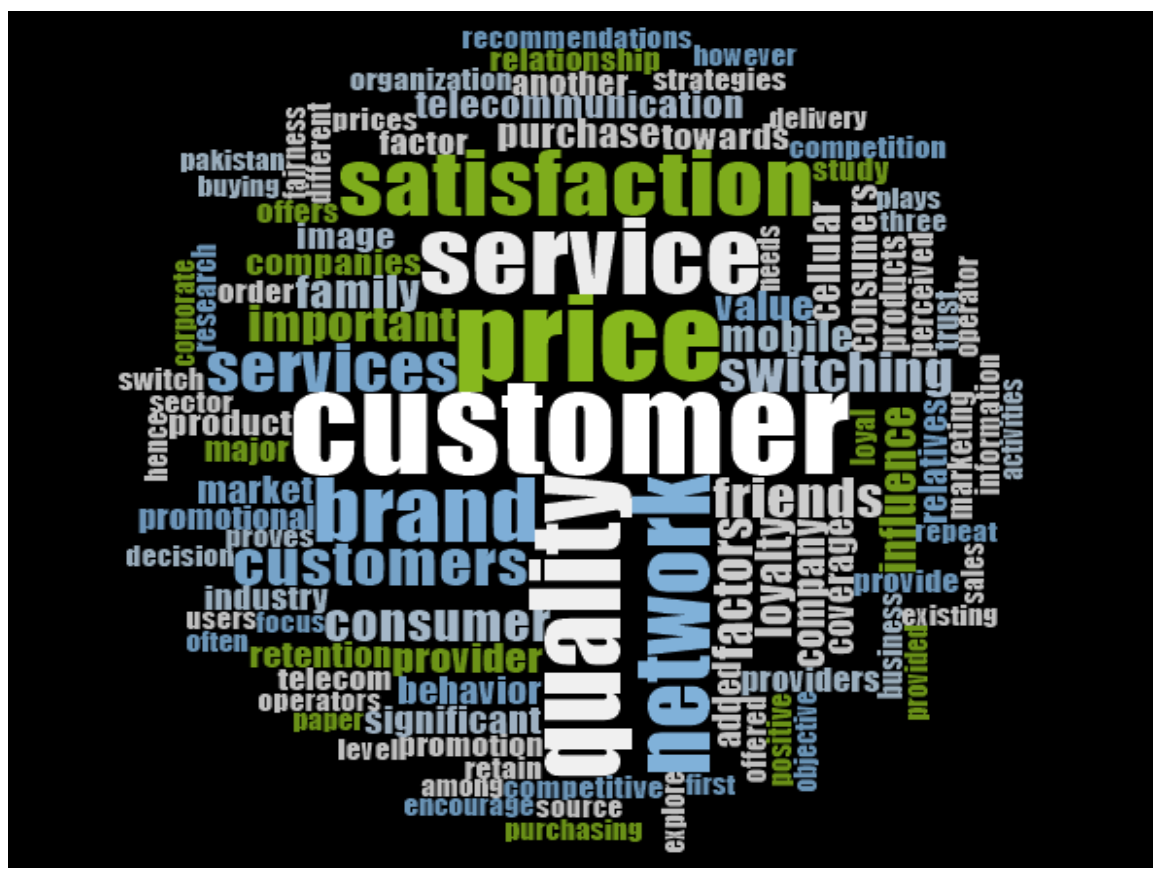

